\title{
Assessment of management decisions as a factor in the sustainable functioning of an enterprise.
}

\author{
A.F. Stepus ${ }^{1}$, O.M. Perminova ${ }^{2}$, and R.V. Faizullin ${ }^{3}$ \\ ${ }^{1}$ Chief Specialist of Axion Corporation LLC, Izhevsk, Russia \\ ${ }^{2}$ Associate Professor of the Management Department. Kalashnikov Izhevsk State Technical \\ University, Russia \\ ${ }^{3}$ Associate Professor of the Department of Information Technologies in Public Administration, \\ Institute of Management Technologies, MIREA — Russian technological university Moscow, Russia
}

\begin{abstract}
The cost of managerial labor, especially managers of the top, middle and lower levels of management, is estimated by various methods, the article proposes to assess through the tension, intensity and complexity of labor by levels of management. This is especially important in times of crisis, when it is required to actively seek better conditions for the enterprise, to organize the work of subordinates in accordance with the new requirements. With an increase in costs and a decrease in the effectiveness of the management staff, in particular, the risk of bankruptcy and a significant decrease in the competitiveness of the enterprise in such conditions of instability increases rapidly. The criticism of macroeconomic indices is carried out and a microeconomic analysis and a method for assessing the intensity, intensity and complexity of labor at different levels of management are proposed. It is known that the most significant costs that have reserves for reduction are personnel costs, including management costs. Based on the analysis of the correlation and mathematical dependence, the ratio of wages by levels of management on a contract basis was determined based on the minimum established level of wages at the enterprise.
\end{abstract}

\section{Introduction}

In the context of the current financial crisis and the threats of instability that surround enterprises everywhere, the most important factor is the risks that enterprises face when making management decisions at all levels. A number of articles by such authors as E. Zavyalova, D. Kucherov, V. Tsybova [1], as well as A. Shamsi [2]. They have been written about the role of management personnel and the competencies of the management itself. First of all, it would be possible to use macroeconomic indices to assess management personnel, but they are not suitable for a number of reasons. Assessment of the human development index - an integral indicator calculated annually for cross-country comparison and measurement of the standard of living, literacy, education and longevity as the main characteristics of the human potential of the study area. This macroeconomic indicator was 
developed in 1990 by a group of economists led by Pakistani Mahbub-ul-Haq [3]. However, the conceptual structure of the index was created thanks to the work of Amartya Sen $[4,5]$. The index has been published by the UN in its annual Human Development Report since 1990. The index has been published by the UN in its annual Human Development Report since 1990. The coefficient of differentiation of the index of health (longevity) does not show what factors contributed to the increase in longevity, without which it is impossible to control the process of increasing longevity. In turn, the coefficient of differentiation of the education index reflects the duration of education, which speaks of the quantity, not the quality of education in the country. The coefficient of differentiation of the income index in monetary terms of one of the compared countries is incorrect, although the estimate of income in consumer budgets would allow to give a broader idea of the real income, taking into account the standard of living, which differs in each country and the high standard of living for one country is low for another. The macroeconomic index does not reveal the true competitiveness of an individual or a group of people united by some principle (region, enterprise, direction, division and structural link), although these indicators should characterize the manager who heads the corresponding group of workers. Therefore, the competitiveness of personnel must be considered through the information interaction of the employee - the workplace - the result of work at the micro level.

\section{Materials and Methods}

\subsection{Concepts and fundamentals of the microeconomic method}

However, it is important to consider not the macroeconomic, but the microeconomic level for the analysis of management decisions, as G. Becker states in his work [6]. In the course of decision-making, any manager is guided by his wealth of knowledge, skills, experience and, based on the formed competencies, makes his decisions with varying degrees of quality. In the traditional sense, such criteria are in the concept of thesaurus. A thesaurus is a quantitative level of quality of collectively adopted management decisions, agreed and documented, based on the experience of communication between labor resources. The concept of "thesaurus", the hidden wealth of knowledge, cannot be measured if the value of such accumulated wealth is assessed from an employee, since his hidden wealth (knowledge) is constantly changing, every second, but if we consider an enterprise, then the thesaurus can and should be assessed as the accumulated experience of management. The accumulation of the thesaurus and the degree of participation in its accumulation will make it possible to quantify the result of the work of managers who make accumulated managerial decisions. Many specialists of the enterprise spend almost all their working time on analytical reports and notes, the result of which are some conclusions, or a variety of measures to solve the identified problems. As a result of the variety of analytical information, management personnel, as the most responsible and experienced category of workers, makes the final decision on the problem. This kind of decision is fixed by organizational and administrative documents, such as: orders, instructions, depending on the competence and level of decision-making. Orders can be issued only by the first person - the director, orders that are mandatory only for a number of services and departments - the deputy director for the direction (for example, the chief engineer). As a rule, any order does not appear without previous experience in this kind of activity, therefore it is released in the development of previously adopted decisions (orders), either canceling, or changing, or supplementing them. So the sequence of orders gives rise to a process nature, which is close to the algorithmic information approach to measuring the amount of information by A.N. Kolmogorov [7]. However, this is only a methodological basis for the development of 
the final equation for calculating the number of orders, qualitatively measured, from the standpoint of various kinds of criteria.

\subsection{Scale for assessing the complexity of control}

So the accumulation of these quantitative assessments of the value of organizational and administrative documents that approve procedures, regulations, instructions, regulations, methodological instructions, standards - this is the thesaurus, the accumulated experience of management. Each specialist, a grassroots leader from a leading specialist and head of a bureau to the head of a direction (deputy general director) who took part in the development of an organizational and administrative document must take upon himself these units of measurement of the value of decisions made and recorded in official documents. The standard for the value of the thesaurus, its development is the purpose of this section. It should be carried out by specialists and managers. Value, or its main characteristic - utility, is the main category of the theory of the desirability function. When this or that decision is made, one or another organizational and administrative document is issued, then both the management personnel and specialists (main and auxiliary personnel) entrust the achievement of the desired goal to its implementation. In this part, it is relevant to mention the numerical marks of the scale of values of the desirability function in table 1.

Table 1. Scale of the desirability function.

\begin{tabular}{|c|c|}
\hline $\begin{array}{c}\text { Quantitative marks on } \\
\text { the scale }\end{array}$ & Desirability of properties \\
\hline $0,80-1,00$ & Very favorable \\
\hline $0,63-0,80$ & Useful \\
\hline $0,37-0,63$ & Agree \\
\hline $0,20-0,37$ & Little useful \\
\hline $0,00-0,20$ & Useless \\
\hline 0 & Dangerous (Destructive) \\
\hline
\end{tabular}

\subsection{Criteria and indicators for assessing the level of management}

Evaluation of all orders on such a scale makes it difficult for an expert to work without definite and precise criteria for the value of the thesaurus. With these criteria, after analyzing the works on competitiveness and productivity, T.V. Khlopova [8], P.A. Shutova [9], are seven main properties of organizational and administrative documents (criteria): the type of process document (regulation, instruction, standard, procedure or regulation) approved by order, order, and for each type of document it is necessary to develop a separate standard; volume (number of characters, printed sheets, in kilobytes); content (the number of sections, applications in this process document); relationship with other documents, processes (number of references to other orders, regulations, instructions, standards); the length of the process, the number of pre-existing process documents for this type of activity; quality, the accumulated period of the process under consideration (the number of years from the creation of the first, previous, or this document), which characterizes the quality of the mechanisms in terms of the implementation of the decisions made (assessment of the durability, efficiency of the document and the process that it regulates); coverage by a document or process of activity of all or part of structural units (share of participating units in the total number of units of the enterprise). Process documents - should be called provisions, instructions, methodological instructions, standards, procedures or regulations that describe the implementation of certain managerial 
decisions, various mechanisms of calculation or sequence of activities of certain categories of personnel.

\subsection{Development of a formula for evaluating management decisions}

However, a number of criteria give rise to the need to take them into account, to bring them to the general value of the value of the thesaurus. This reduction is achieved either by a simple arithmetic average, or by the development of various kinds of econometric or expert assessments of the weight coefficients of these properties (criteria). If at least one of the indicated properties is equated to " 0 ", then the entire value of the document must be reduced to " 0 ". So, for example, there are a number of orders for the enterprise, which are approved by the director of the enterprise, on the appointment of a materially responsible person. For the assessment of the thesaurus, the accumulated experience of management decisions made, management experience, these orders do not have any value, or personnel orders that are not of value, according to the subject of our research. Such facts occurring in socio-economic reality dictate the need to use the geometric mean, which leads to the value of " 0 " the total value of the thesaurus, if at least one of the properties, one of the criteria does not fully meet the requirements, that is, it is also equal to " $0 "$. So, the formula for calculating the value of the thesaurus on the scale of the desirability function is as follows.

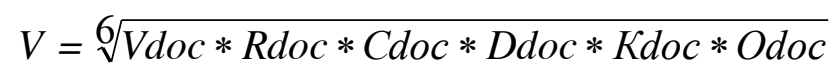

where $\mathrm{V}$ - the value of the management decision thesaurus approved by this type of organizational and administrative document (two types: regulations, instructions, orders, lists; standards); V doc - the corresponding quantitative value of the assessment on the scale of the desirability function of the volume of the organizational and administrative document (the number of characters without spaces); $\mathrm{R}$ doc - the corresponding quantitative value of the assessment on the scale of the desirability function of the relationship of the process document with other documents (the number of references in the document); $\mathrm{C}$ ord - the corresponding quantitative value of the assessment on the scale of the desirability function of the content of the process document approved by the organizational and administrative document (the number of sections, starting with the "general provisions"); D ord - the corresponding quantitative value of the assessment on the scale of the desirability function of the length of the process, the number of pre-existing documents on the implementation of the decision, enshrined in this organizational and administrative document; $\mathrm{K}$ ord - the corresponding quantitative value of the assessment on the scale of the desirability function of the quality of the decision made (the number of years from the creation of the first document in the direction of activity); Odoc - is the corresponding quantitative value of the assessment on the scale of the desirability function of coverage, involvement of other structural units in the implementation of the decision taken (share in the total number).

\subsection{Development of criteria levels with relative assessments}

It is necessary to take into account and provide for the possibility of automating such an assessment of the thesaurus of management personnel, which, accumulating in a separate area of activity (service), department (workshop), bureau (laboratory), reflects the labor potential for analytics. So only with automation it is possible to quantitatively take into account such a base of methodological instructions, provisions, instructions developed earlier. The complexity and quality must be taken according to the existing scale, while the more difficult the decision to make in implementation, the higher the score should be. These criteria should be evaluated by a team of experts competent in the given field of 
activity. For the rest of the criteria, the following scales can be set according to table 2 .

Table 2. Bringing the actual values of the criteria to the scale of the desirability function according to process documents.

\begin{tabular}{|c|c|c|c|c|c|c|}
\hline $\begin{array}{c}\text { Desirability } \\
\text { scale }\end{array}$ & V doc & R doc & $\begin{array}{c}\text { C } \\
\text { doc }\end{array}$ & $\begin{array}{c}\mathbf{D} \\
\mathbf{d o c}\end{array}$ & $\begin{array}{c}\text { K } \\
\text { doc }\end{array}$ & O doc \\
\hline 1,00 & $>14000$ & $>12$ & $\begin{array}{c}7 \text { и } \\
>\end{array}$ & $>3$ & 3 и $>$ & $>0,50$ \\
\hline 0,80 & $>10000$ & $9-12$ & $\begin{array}{c}5- \\
6\end{array}$ & 3 & 2 & $>0,40$ \\
\hline 0,63 & $>6000$ & $6-9$ & $\begin{array}{c}3- \\
4\end{array}$ & 2 & 1 & $>0,20$ \\
\hline 0,37 & $>3000$ & $3-6$ & 2 & 1 & - & $>0,02$ \\
\hline 0,20 & $>500$ & $1-3$ & 1 & - & - & 0,02 \\
\hline 0 & $<500$ & 0 & - & - & - & 0 \\
\hline
\end{tabular}

\section{Results and Discussion}

\subsection{Application of the methodology in practice and determination of average parameters for groups of managers}

The actual values are derived on the basis of the average statistical sample, according to the data of organizational and administrative documents for 2 years. They also served as the basis for assessing the result of labor (in the sum of the accumulated value of the thesaurus of managerial decisions) of such categories of personnel as: leading specialist, shift foreman, shift supervisor; head of bureau, laboratory, senior foreman, head of the site; head of department, shop, service, department; Deputy Director, Chief Specialist; Director. The share of each is determined by the number of signatures in the document, including the performer (the leading specialist who developed the document), as a result, each of the categories had a certain value of the accumulated adopted management decisions, the sums of the values of the management thesaurus. Taking into account this share, about two and a half thousand organizational and administrative documents approved during the year had the following distribution by categories of complexity of management personnel. Taking into account this share, about two and a half thousand organizational and administrative documents approved during the year had the following distribution by categories of complexity of management personnel. As a result, it is possible to obtain the ratio of the coefficients between the levels of management and bring them to the tariffication system in labor units of measurement, developed by S.G. Strumilin [10]. The obtained labor units make it possible to determine the coefficients of correlating the levels of earnings of managers with the 1 st level of the minimum wage adopted at the enterprise, it must not be lower than the level adopted in the region of the Russian Federation.

Table 3. Definition of coefficients of labor units of measure based on the growth of the thesaurus of management personnel.

\begin{tabular}{|c|c|c|c|c|c|}
\hline Parameter & $\begin{array}{c}\text { Leading } \\
\text { specialist }\end{array}$ & $\begin{array}{c}\text { Head of } \\
\text { bureau }\end{array}$ & $\begin{array}{c}\text { Head of } \\
\text { department }\end{array}$ & $\begin{array}{c}\text { Deputy } \\
\text { director }\end{array}$ & Director \\
\hline Rank & 13 & 14 & 15 & 16 & 17 \\
\hline $\begin{array}{c}\text { Labor units for measuring the } \\
\text { complexity of work S.G. }\end{array}$ & 4,8 & 5,4 & 6 & 7 & 8 \\
\hline
\end{tabular}


Table 3. Continued.

\begin{tabular}{|c|c|c|c|c|c|}
\hline Strumilina & & & & & \\
\hline Results V & 208 & 237 & 270 & 308 & 351 \\
\hline Growth rate & - & 1,14 & 1,14 & 1,14 & 1,14 \\
\hline $\begin{array}{c}\text { Coefficients of labor units of } \\
\text { measure }\end{array}$ & 4,8 & 5,5 & 6,25 & 7,1 & 8,1 \\
\hline
\end{tabular}

\subsection{Comparison of grading by level of management and analysis of deviations}

Analysis obtained in table. 3 coefficients of labor units of measurement using the SPSS program allows you to find the most accurate mathematical dependences on the category of the qualification level of the manager. Table 4 below is an analysis of the obtained coefficients of labor units of measurement.

Table 4. Analysis of the mathematical dependences of the coefficients of labor units of measurement on the category.

\begin{tabular}{|c|c|c|c|c|c|c|c|}
\hline \multirow{2}{*}{$\begin{array}{l}\text { Ran } \\
k / \\
\text { level }\end{array}$} & \multirow[b]{2}{*}{$\begin{array}{c}\text { Labor } \\
\text { unit }\end{array}$} & \multicolumn{2}{|c|}{$\begin{array}{c}\text { Quadratic } \\
\text { dependence }\end{array}$} & \multicolumn{2}{|c|}{ Power dependence } & \multicolumn{2}{|c|}{$\begin{array}{l}\text { Exponential } \\
\text { dependence }\end{array}$} \\
\hline & & $\begin{array}{c}1.315- \\
0.066 * \mathrm{P}+ \\
0.026 * \mathrm{P}^{2}\end{array}$ & $\begin{array}{c}\text { Relative } \\
\text { deviatio } \\
n\end{array}$ & $\begin{array}{c}0.943^{*} \\
1.134 * * \mathrm{P}\end{array}$ & $\begin{array}{l}\text { Relative } \\
\text { deviatio } \\
n\end{array}$ & $\begin{array}{c}0.943 * \mathrm{e}^{\left(0.125^{*}\right.} \\
\text { P) }\end{array}$ & $\begin{array}{l}\text { Relative } \\
\text { deviatio } \\
\text { n }\end{array}$ \\
\hline 13 & 4,80 & 4,85 & 0,01 & 4,84 & 0,01 & 4,79 & 0 \\
\hline 14 & 5,50 & 5,49 & 0 & 5,48 & 0 & 5,43 & $-0,01$ \\
\hline 15 & 6,25 & 6,18 & $-0,01$ & 6,22 & 0 & 6,15 & $-0,02$ \\
\hline 16 & 7,10 & 6,92 & $-0,03$ & 7,05 & $-0,01$ & 6,97 & $-0,02$ \\
\hline 17 & 8,10 & 7,71 & $-0,05$ & 8,00 & $-0,01$ & 7,90 & $-0,03$ \\
\hline
\end{tabular}

\subsection{Results of distribution by management levels}

The largest number of coinciding values gives an exponential relationship that is closest to reasonable labor units, in particular, level 13 corresponds to the leading specialist, 14 to the level of the head of the bureau, 15 to the level of the head of the department, 16 to the level of the deputy director and 17 to the level of the director, and the calculation formula the complexity of management in labor units will have the form.

$$
\text { Klabor.unit. }=0,943 \cdot 1,134^{\text {Rank }}
$$

\section{Conclusion}

This formula can be used to assess the categorization and ratio of the level of remuneration for managers of an enterprise at all levels of management when applying the time-based wage system, in terms of constant wages, by multiplying the corresponding coefficient by the level of the minimum wage established at the enterprise. Along with a constant salary, it is possible to recommend approximately $60 \%$ to establish a variable salary depending on the indicators of profit, revenue and performance of the enterprise, as well as apply quarterly and annual bonuses. This system will take into account the tension and complexity of the work of the management personnel of an industrial enterprise. 


\section{References}

1. E. Zavyalova, D. Kucherov, V. Tsybova, FORESIGHT, 4 (2017)

2. A. Shamsi, FORESIGHT, 4 (2017)

3. Multidimensional Poverty Index 2020: Charting pathways out of multidimensional poverty: Achieving the SDGs (2020)

4. A. Sen, Inequality Reexamined (1992)

5. J. Stiglitz, A. Sen, J. P. Fitoussi, Miscalculating Our Lives: Why Doesn't GDP Make Sense? 216 (2016)

6. G. S. Becker, The Economic Approach to Human Behavior (1976)

7. A. N. Kolmogorov, Three approaches to the definition of the "amount of information", 1 (1965)

8. T. V. Khlopova, Competitiveness of an employee of an enterprise, 9, 82 (2002)

9. P. A. Shutova, Competitive personnel - a source of growth in the competitiveness of products, 150 (2007)

10. S. G. Strumilin, Selected works in 5 volumes (1965) 